\title{
Australian agriculture: coping with dangerous climate change
}

\author{
Will Steffen • John Sims $\cdot$ James Walcott $\cdot$ \\ Greg Laughlin
}

Accepted: 24 October 2010

(C) Springer-Verlag 2010

\begin{abstract}
Australian agriculture has operated successfully in one of the world's most hostile environments for two centuries. However, climate change is posing serious challenges to its ongoing success. Determining what might constitute dangerous climate change for Australian agriculture is not an easy task, as most climate-related risks are associated with changes in the highly uncertain hydrological cycle rather than directly to more predictable changes in temperature. In addition, the adaptive capacity of Australian producers is generally high, as they have had to cope with a highly variable climate in which periodic, severe droughts are the norm. As the underlying global trends in climate interact with the continent's patterns of natural variability, producers can generally deal with gradual changes in climate but are most concerned about high rates of change in regional and local climates and with abrupt, unexpected shifts in climate patterns. Perhaps the best indicator of dangerous climate change for Australian agriculture is the persistence, or not, of the drying trends in many of the Country's most productive regions and the strength of the linkage between these trends and global climate change.
\end{abstract}

\section{W. Steffen $(\bowtie)$}

The ANU Climate Change Institute, The Australian National University, Canberra, ACT 0200, Australia

e-mail:will.steffen@anu.edu.au

\section{J. Sims · J. Walcott · G. Laughlin}

Climate Change, Land and Forests, Australian Bureau of Agricultural and Resource Economics-Bureau of Rural Sciences, Department of Agriculture, Fisheries and Forestry, Australian Government, Canberra, Australia

Present Address:

G. Laughlin

Australian National Data Service, Monash University and Australian National University, Canberra, Australia
Keywords Agricultural impacts - Effects of drought · Adaptive capacity $\cdot$ Climate risks to agriculture

\section{Introduction}

Determining what may be tolerable levels of climate change for Australian agriculture is a daunting task and differs from similar attempts in other parts of the world, especially the northern hemisphere, in several significant ways. First, for most types of Australian agriculture, water availability is a more important climate-related parameter than temperature, making temperature-based estimates of "dangerous climate change" based on scenario analysis less useful for Australian agriculture than for other sectors and other countries. Second, because of Australia's high natural climate variability, many producers and agricultural industries already have high adaptive capacity with regard to climate pressures. Third, given that Australia is a large continent spanning tropical, sub-tropical and temperate climatic zones, there is enormous variability in the types of agriculture undertaken in the country, in the sensitivity of the various industries to a changing climate and in their adaptive capacity.

Here, we explore the nature of climatic risks to, and the adaptive capacity of, Australian agriculture in the context of attempting to determine what might constitute dangerous levels of climate change (cf. Article 2 of the United Nations Framework Convention on Climate Change, UNFCCC 1992). We first describe the nature of Australian agriculture as a background for examining the sensitivity of Australian agriculture to current and future climate risks. Next, we discuss the sector's adaptive capacity to deal effectively with climate risks. Both sensitivity and adaptive capacity are required to estimate the sector's vulnerability 
to climate change. Then, we describe contemporary climate trends in Australia, with a special emphasis on those of importance for agriculture. Finally, we analyse the most significant climate risks for Australian agriculture through the twenty-first century in the context of what types and levels of climate risks might be tolerable and what might be beyond the limits of adaptability.

\section{Nature of Australian agriculture}

Australian primary producers operate in one of the world's most hostile environments for agriculture. Australia is the driest inhabited continent, it has a high degree of climate variability, and its soils are generally poor in both nitrogen and phosphorus. Despite these constraints, over the past 200 years, Australian agriculture has developed not only to supply a large proportion of the food requirements for 22.5 million Australians, but also to become a significant agricultural exporting nation.

Figure 1 shows the distribution of agricultural land use across the continent. Cropping systems are concentrated in a belt from central Queensland through central New South Wales and around the southeast corner of the continent into Victoria and South Australia. The south-western corner of West Australia, with its pronounced Mediterranean climate, is the other region of significant cropping activity. The boundaries of these cropping regions towards the interior of the continent are defined by moisture availability. Grains dominate the cropping sector, with wheat being the most important single crop. Horticulture and viticulture, however, are growing in importance.

Most of Australia's cropping regions are areas of mixed agriculture, with the grazing industry also playing a major

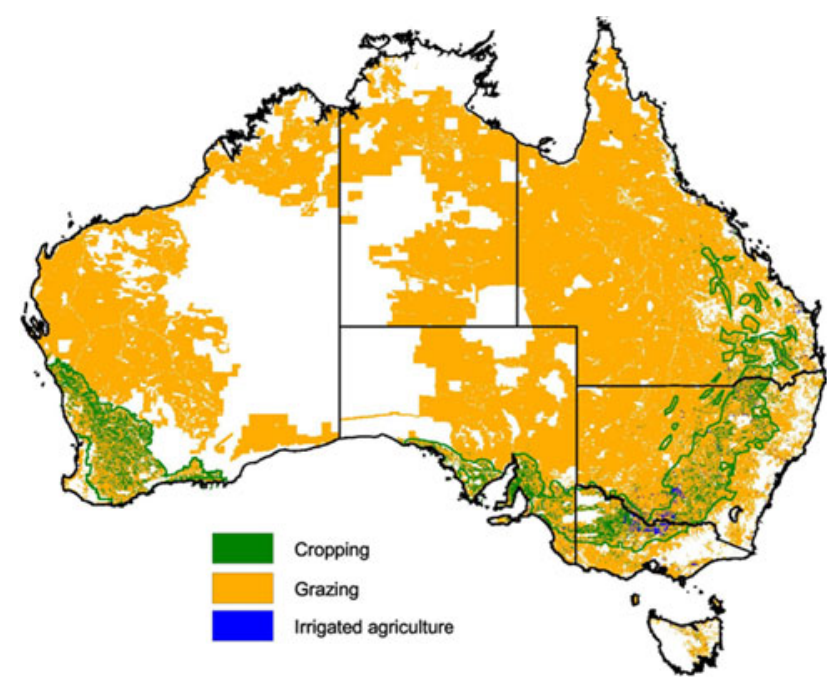

Fig. 1 Map of land use across Australia, showing major agricultural zones in the continent role. The belt of mixed grazing-cropping from southern Queensland around into Victoria, the so-called wheatsheep region, is the traditional backbone of Australian agriculture. The grazing industry covers by far the most land area under agriculture, with large semi-arid and arid regions across the north and centre of Australia used mainly for cattle production. Although important in an economic sense, irrigated agriculture occupies a very small fraction of Australia's land area. The most significant concentration of irrigated agriculture is located in the south-central region of the Murray-Darling basin.

The productivity of Australian agriculture on an annual basis correlates strongly with the well-known El NiñoSouthern Oscillation (ENSO) phenomenon and the Indian Ocean Dipole (IOD), along with a number of other climatic influences like the Madden-Julian Oscillation (MJO), the Southern Annular Mode (SAM) and the subtropical ridge. The subtropical ridge is a zone of high pressure that usually lies over the south of the continent in summer and migrates northward in winter. Its northward movement allows cold fronts that are embedded in the westerlies to bring rain to Australia's 'Mediterranean regions'. Although it is not yet clear, it seems likely that ENSO and the IOD (and possibly the SAM) interact with each other so that certain combinations of ENSO and IOD produce the unusually wet or dry years (e.g., Ummenhofer et al. 2009; Hendon et al. 2007; Meyers et al. 2007).

ENSO is a cyclical (events recur on 2- to 7-year intervals) climatic pattern centred in the tropical Pacific Ocean, related to fluctuations between unusually warm and cold ocean conditions. The phenomenon involves an intricate coupling between Pacific trade winds, atmospheric pressure and sea surface temperature. Although centred in the tropical Pacific Ocean, ENSO has global effects through teleconnections to atmospheric patterns elsewhere on the planet (McPhaden et al. 2006).

The IOD is similar in some respects to ENSO and involves fluctuations between unusually warm and cold ocean conditions in the Indian Ocean. The term 'dipole' refers to the tendency of the IOD to oscillate between two states: cool waters around Indonesia and warm water in the western Indian Ocean and warm waters around Indonesia and cool water in the western Indian Ocean. Periods of drier than average conditions appear to be associated with an absence of negative IOD events (Ummenhofer et al. 2009).

The El Niño phase of ENSO is associated with droughts in eastern Australia and thus to reduced agricultural production. The severe droughts in eastern Australia associated with El Niño events in 1982, 1994 and 2002-2003 led to sharp reductions in the net value of farm production. For example, the 2002-2003 drought reduced Australia's Gross Domestic Product by about $1 \%$ (A $\$ 6.6$ billion) and led to 
the loss of about 70,000 jobs (Steffen et al. 2006a). Another El Niño during 2006 and 2007 also came with a widespread drought in southwestern, southern and eastern Australia, continuing an extended period of low rainfall in these regions similar to that of $1895-1903$. Both these periods (1895-1903 and 2002-2009) lacked significant negative IOD events (Ummenhofer et al. 2009).

\section{Sensitivity of Australian agriculture to future climate risks}

The ways in which Australian agriculture deals with natural climate variability and the ways in which it is coping with the climatic trends of the twenty-first century give important insights into its sensitivity to current and future climate risks. The increasing recognition that climate change intensifies some of the risks associated with climate variability and perhaps presents new risks has led to an ongoing consultative process among producers, industry representatives, researchers and policy makers to ensure the continued sustainability and profitability of Australian agriculture in the face of a changing climate (Steffen et al. 2006b).

Complementary to this process, Hennessy et al. (2008) used General Circulation Model (GCM) outputs to investigate the impact of climate change on the nature and frequency of exceptional climatic events, focusing on droughts. They showed that the extent and frequency of exceptionally hot years has increased over recent decades and is likely to continue for the next 40 years at least; this trend was evident generally across the country. The trend for exceptionally low rainfall years was less generalbecause of decadal variability - but certain areas, like the southwest of Western Australia, showed a clear trend towards more frequent and more severe dry events.

Although the sensitivity to climate varies considerably across Australian industry according to the nature of the production system, there are some general features of climate to which most Australian agricultural industries are sensitive. Most of these features are related to the hydrological cycle and, in particular, to the timing of moisture availability through the growing season. Knowledge about other water-related parameters, such as stream flow, overland flow and relative humidity, is often more useful in management applications than is rainfall per se. Linking these climate-related parameters to underlying trends in mean temperature, the commonly used indicator of climate change, is very difficult, complicating the task of defining what might be dangerous levels of climate change for Australian agriculture.

There are, however, some other specific features of climate that are more closely related to temperature to which particular Australian industries are sensitive (Steffen et al. 2006b), for example:

- Annual cropping: The grains industry, Australia's largest crop-based industry, is sensitive to the timing of frosts with respect to the phenology of the plant and to cumulative temperature sums.

- Dairy cattle: The dairy industry is one of the more vulnerable to rising temperatures due to the sensitivity of dairy cattle to heat stress (high temperature coupled with high humidity).

- Horticulture: Higher night temperatures are a risk for some late harvested varieties of fruit, maximum temperature limits exist for some varieties, and chilling requirements are common for many varieties.

In addition to the direct impacts of changes in moisture availability and temperature on production systems, many producers identified that indirect climatic effects are just as important as the direct effects for the viability of Australian agriculture. The most important of these is the change in the distribution or incidence of pests and diseases, a risk of particular importance for Australia given its isolation from many of the world's common agricultural pests. For the cattle industry, arbovirus, bluetongue, cattle ticks and buffalo fly present important risks for the animals themselves, while invasion of tropical weeds in pastures in southern Australia is also a cause for concern. A major indirect threat to the cropping industry is the potential spread of climate-sensitive animal pests, such as locusts and mice.

Climate scenario-based studies of climate impacts on Australian agriculture, summarized in Pittock (2003), generally reinforce the analysis of the sensitivity of Australian agriculture to climate based on the consultative approach. In addition, the scenario studies point to two additional temperature-related effects that could become important in the longer term-(1) direct heat stress on plants or crop deterioration during heat waves and (2) more rapid phenological progress of the plants through the growing season, leading to both potential benefits and costs.

A comprehensive study of the impacts of climate change at 2070 on the wheat industry (Howden and Jones 2001) showed a slight increase in mean production of $1.8 \%$, when adaptation and the $\mathrm{CO}_{2}$ fertilization effect are included. That result, coupled with the fact that technological, management and socio-economic changes to the industry will be substantial by 2070 , may give cause for optimism. On the other hand, the study and a subsequent study by Howden and Crimp (2005) also showed much larger potential increases and decreases in production, depending on region, the nature of the climate scenario (the combinations of temperature increase and rainfall change) and the level of adaptation assumed. 
Consultations with producers (Steffen et al. 2006b), however, have highlighted two features of climate change that are critical in determining what constitutes dangerous climate change for them: (1) whether climate change occurs at a rate beyond which they are unable to adapt and (2) whether climate change occurs as major, abrupt shifts rather than gradual changes in underlying means with current variability (even though this leads to more extreme events). The challenge associated with abrupt changes is that they are usually not expected and thus are not planned for, and also because abrupt changes of sufficient magnitude may push some industries beyond their operational thresholds. Again, abrupt changes associated with the hydrological cycle are, in general, of more concern to Australian agriculture than those associated directly with temperature.

\section{Adaptive capacity}

We consider adaptive capacity to be the ability, or ease, with which farmers can adapt agricultural production systems to be profitable under new climatic patterns. This brief view of some elements that contribute to adaptive capacity of Australian agriculture is unable to explore the different components that may be important for different regions and sectors. It extrapolates from historical changes only up to 2030 , or $1^{\circ} \mathrm{C}$ rise in mean temperature, because of a lack of tools to predict future requirements in adaptive capacity sufficiently well to use in decision-making. We consider the adaptive capacity for climate change within the context of a range of other factors, such as technological development, family and social values, and management practices, that pose risks to farm enterprises and industry viability.

Agriculture in Australia has been autonomously adapting to a variable climate since Europeans began settling Australia about 200 years ago. As more experience was gained, accommodations were made to the vagaries of climate, especially with regard to droughts. Adapting to a highly variable climate is not new. Studies of paleoclimates and archaeology of Australia over the past 50,000 years show that continual and sometimes quite remarkable environmental change is normal but that people-both Indigenous and European Australians-are remarkably adaptable and resilient, managing the change in their environments so that life goes on in a viable way (Lilley 2006). Lilley's long-term sanguine view is supported in the short term to medium term by anecdotal responses of agricultural industry leaders (Steffen et al. 2006b) that they can handle gradual change in underlying climatic averages, even if it involves shifts in the incidence of extreme events, through good management. A subjective assessment by scientists rated the adaptability of agricultural sectors to individual impacts from climate change as medium or high (see Table 10 of Pittock 2003) but rigorous assessments of adaptive capacity face difficulties because they are likely to require context-specific, location-specific analyses, actively involving stakeholders and decision makers (Walcott and Wolfe 2008).

Nevertheless, a recent contribution to agricultural policy in Australia (Agriculture and Food Policy Reference Group 2006) notes that while adaptation has always been a hallmark of Australian rural life, adapting to change is not always easy. For those in the middle of a drought, there is considerable physical hardship, social heartbreak, animal suffering and economic losses. Moreover, it is not just rainfall deficiency that caused these impacts in semi-arid regions but other factors such as management (overexpectation of productive capacity, inability to destock), government policy and low world commodity prices can contribute to actual impact (McKeon et al. 2004).

At a national level, there is some evidence of the adaptive capacity of Australian agriculture to a variety of short- to medium-term stresses that could be indicative of capacity to adapt to abrupt climate change. For example, recent changes in land use and intensity (Walcott et al. 2001) show short-term adaptation to market forces and to existing resources with better technologies. Figure 2, produced using an index of changes in the intensification of agriculture (NLWRA 2001), shows that the greatest changes in land use intensity occurred around large population centres and irrigation areas and then in the broad crescent that curves around inside the east coast, around the south coast to the southern part of the west coast of Australia, and includes the island of Tasmania. These areas have adapted

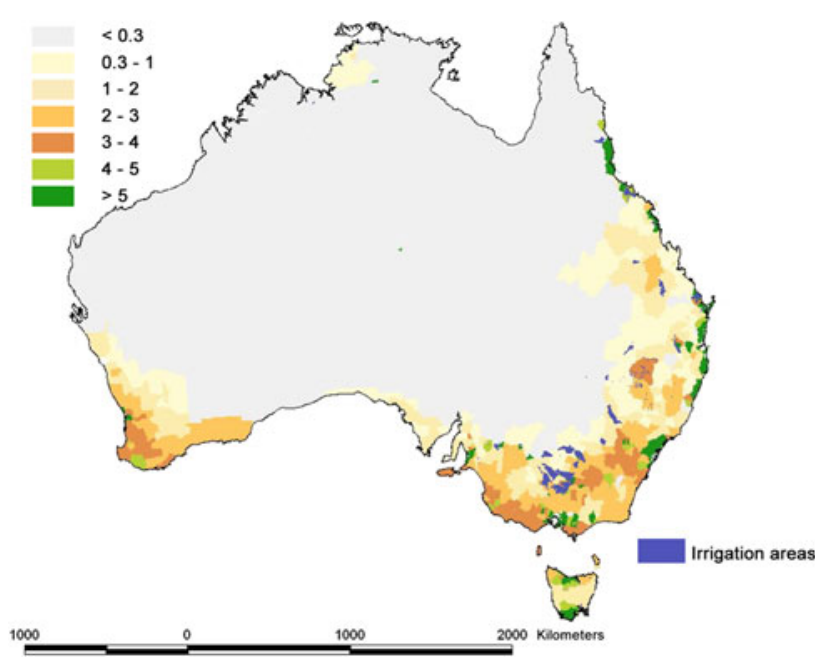

Fig. 2 The range (maximum less minimum) in values of agricultural land use intensity index that occurred during 1982/1983 to 1996/2007. (Adapted from NLWRA 2001, Fig. 7.4) 
well to changing economic and technological opportunities. The areas further inland appear to have changed less, probably because of fewer viable land use options.

Adaptation strategies vary with region. Within cropping areas, for instance, there has been continuing diversification in recent years (Kingwell 2006; Walcott 2004) which, along with other innovations, has allowed the national average wheat yield under drought to increase although at a somewhat lower rate than under normal conditions (NLWRA 2001). By contrast, the interior areas, with fewer options for changing land use due to low and more erratic rainfall, have concentrated on improving their management of existing enterprises, such as more rapid movement of livestock in response to pasture availability, and sometimes shifting enterprises from wool to meat sheep or from sheep to cattle.

An analysis of vulnerability to structural adjustment in the broadacre agricultural industries in Australia (Nelson et al. 2005) used indicators of human, social, natural, physical and financial capital. High vulnerability often suggests low adaptive capacity. The analysis found that the areas of highest vulnerability were located in a loose band to the interior of the cropping belt around Australia, with another band along the east coast of the continent, often associated with the sheep industry but sometimes with beef production and usually on smaller farms.

Australian farmers are becoming more aware of climate change and more interested in adapting to its potential impacts. The issue is causing industries and governments some concern about when to take actions (i.e., timing of decisions) because of the risks that planned improvements in adaptive capacity may incur costs that render industries less competitive on international markets. One impact of climate change may be a loss of embedded information (Quiggin and Horowitz 2003) about locally specific conditions, given that the past is now a less reliable predictor of future trends. This increases reliance upon regionally specific R\&D.

Planned adaptation, a stepwise process in response to projected regional and sectoral impacts, recognizes that it may require detailed, integrated assessments to better support the understanding and evaluation of trade-offs in making decisions. Major adaptations to climate change are more likely to be called upon with long-lived infrastructure investments such as grain handling facilities, dams, perennial crop species, irrigation systems and farm purchases (Quiggin and Horowitz 2003). Assessing the adaptive capacity required to cope with these longer-term (strategic) decisions and the ability to cope with extreme events (disasters) is difficult because of the uncertainties of future climates, rapidly changing markets and still-emerging technologies but it will likely require a mix of quantitative and qualitative methods (Walcott and Wolfe 2008).
In Australia, government policy is to seek agricultural industries that are inter alia competitive, self-reliant and innovative. Governments can assist in enhancing the resilience and adaptive capacity of agricultural industries and rural communities in various ways (Clark et al. 2006). Government programs to help industries towards these outcomes have included capacity building (risk management skills, community Landcare groups and drought preparedness), innovation (research and development), welfare support (during exceptional droughts), regulation (agricultural and veterinary chemicals) and quarantine (preventing the entry of pests, diseases and weeds). They essentially aim to embed adaptation to climate change within existing policy programs. For instance, the formation of the National Climate Change Adaptation Research Facility in 2008, which includes primary industries as one of it eight priority themes, will provide a significant boost to adaptation research over the next 3-4 years.

In summary, a review by (Kingwell 2006) concluded that Australian farmers, on average, are well placed to respond to climate change, having access to $\mathrm{R} \& \mathrm{D}$ innovation, agribusiness services, education services, modern infrastructure, a range of marketing and storage systems, and are well served by financial markets. Another assessment (Allen Consulting Group 2005) claimed that the extensive livestock and broadacre cropping industries had few adaptive options across most rainfall zones, while more intensive industries had high capacity to adapt. Preliminary estimates that we have made indicate an overall moderate to good adaptive capacity within Australian agriculture. This implies that there will be pain to some sectors in adjusting to changing climates. Ultimately, it is farmers' ability to generate income that will need to remain the focus of their business activity (Kingwell 2006). Farmers will need to be self-reliant and to adapt to climate change and its associated climatic and commodity price variability, with limited government assistance.

\section{Contemporary climate trends in Australia}

The high degree of natural climate variability, particularly in rainfall, across Australia complicates the determination of the longer-term trends of climate change. Nevertheless, the rise in global mean temperature observed over the past century or so is reflected in the Australian record. Figure 3a shows the observation of mean surface temperature over the Australian continent from 1910, when continental-scale instrumental records began, to the present. Although the overall rise in mean temperature, especially during the second half of the twentieth century, is generally similar to the global record, there is more variability in the Australian record. The exceptionally high temperature in 2005 stands 
out, as it easily topped the previous record in 1998. This is unusual as 1998 was an El Niño year, when temperatures are warmer than usual, while 2005 was not. The expected geographical pattern of higher temperature anomalies in the middle of the continent is evident in the 2005 record, as shown in Fig. 3b.

Trends in mean annual rainfall do not show such a clear trend. Figure 4 shows the continental trends in rainfall over the past 50 and 100 years. At the century time scale, there is little change in mean rainfall, with the continent as a whole becoming slightly wetter. Only the southwest corner of Western Australia and a small area on the central Queensland coast have become significantly drier. However, over the past 50 years, the timeframe over which the mean temperature has clearly risen above the longer-term average, a clear spatial pattern has emerged. The northwest part of the country has become much wetter, while a pronounced drying trend has appeared along the east coast, the region where most of the Australian population lives and where much of the agricultural activity occurs. The drying trend in the southwest corner of Western Australia has become more severe. Although we cannot say categorically that this is the result of climate change exclusively, the consistency between GCM predictions for this region is certainly supportive of anthropogenic climate change as a significant driver (e.g., Clark et al. 2006).

In terms of extreme events, Australia has experienced several heat waves in the last decade or so. One such severe event occurred in February 2004, when temperatures were $5-6^{\circ} \mathrm{C}$ above average over large areas of Australia for a three-week period. About two-thirds of the continent reported maximum temperatures during the period of $39^{\circ} \mathrm{C}$ or higher, with several major cities (Sydney, Adelaide, Brisbane) reporting exceptionally high temperatures for continuous periods of a week or more. Again, in January and February of 2009, extremely hot, dry and windy conditions were experienced in southeastern Australia, leading to an extreme heatwave event and damaging bushfires.
Fig. 3 a Australian annual mean temperature anomalies (based on 1961-1990 average) since 1910, and $\mathbf{b}$ annual mean temperature anomalies $\left({ }^{\circ} \mathrm{C}\right)$ across Australia for 2005 (Australian Bureau of Meteorology)

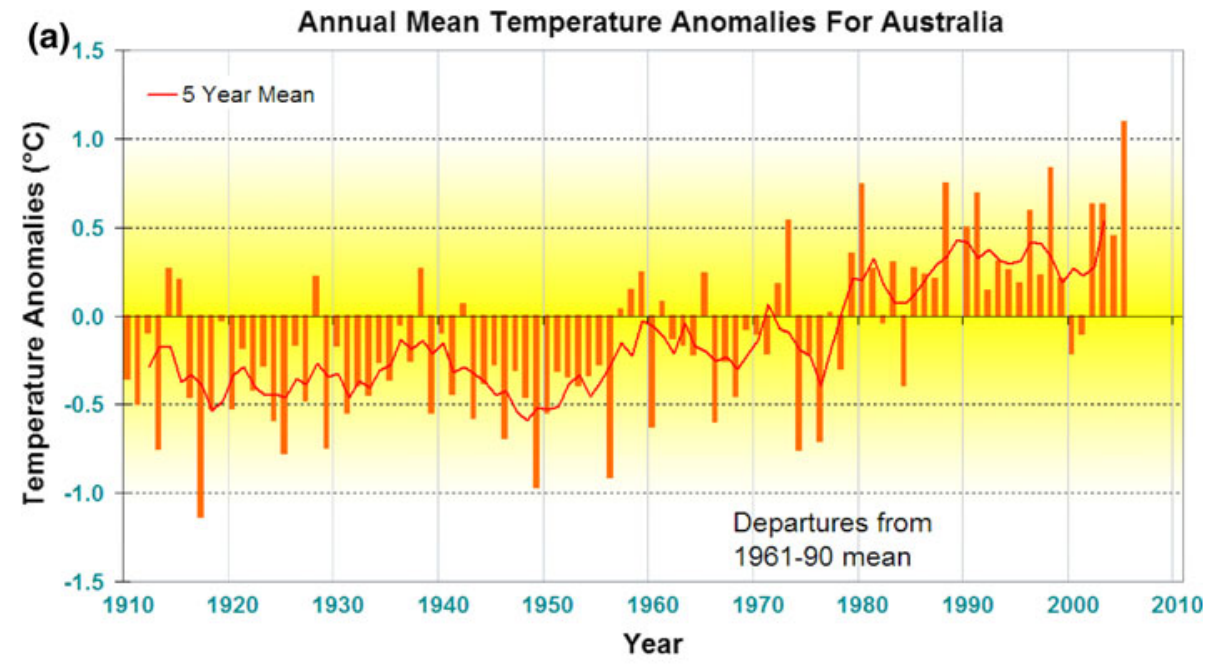

(b)

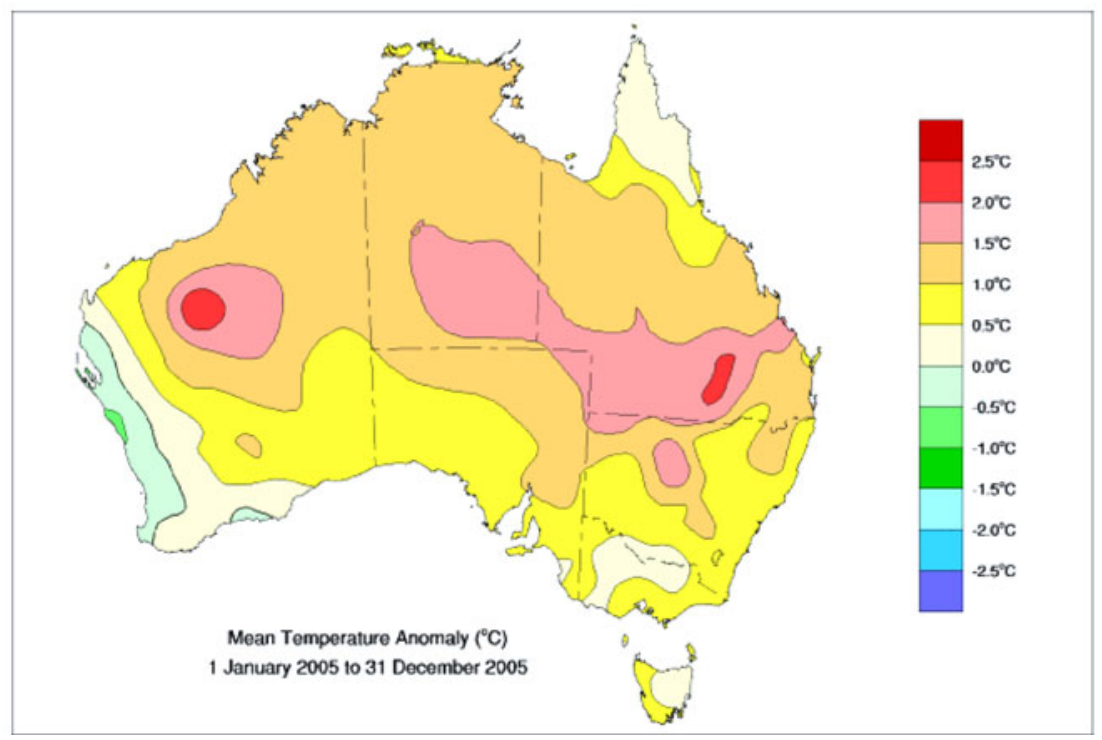




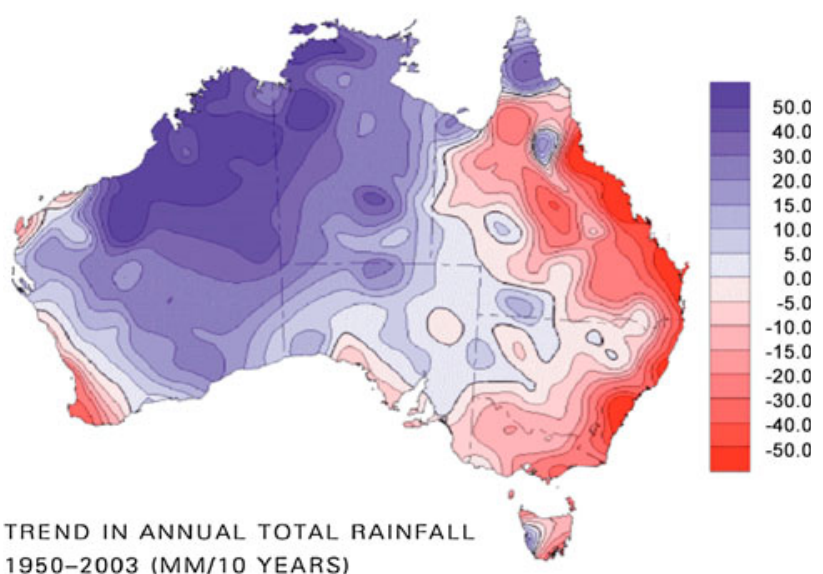

1950-2003 (MM/10 YEARS)

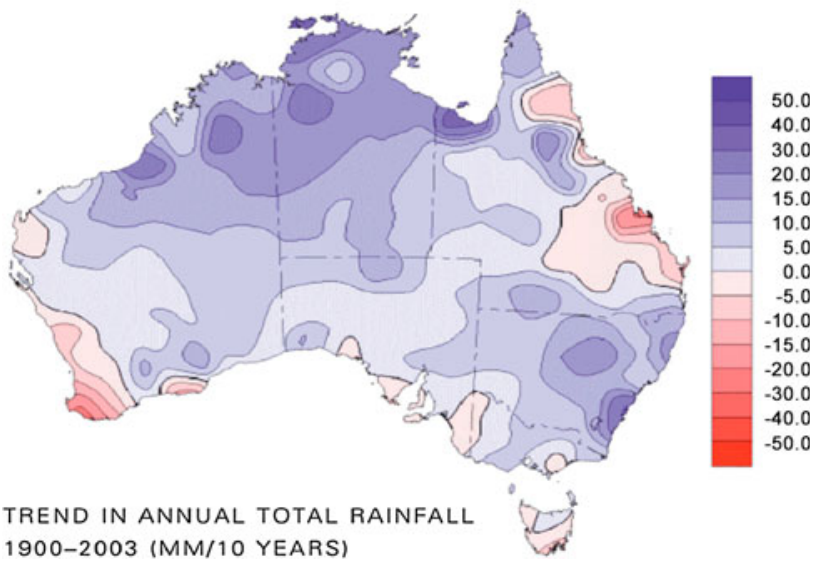

Fig. 4 Trend in annual total rainfall in $\mathrm{mm} / 10$ years over Australia for the past 50 (top) and 100 years (bottom). Blue indicates areas that have become wetter, and red/pink indicate areas that have become drier (Australian Bureau of Meteorology)

Many records were set both for high daytime and nighttime temperatures as well as for the duration of extreme heat. For example, nearly half of Tasmania had its hottest day on record on 30 January, with many records broken by large margins. Over the 5 days, 27-31 January 2009, maximum temperatures were $12-15^{\circ} \mathrm{C}$ above normal over much of Victoria and southern South Australia. On Saturday 7 February, record high temperatures for February were set in over $87 \%$ of Victoria.

Extreme precipitation events occur periodically as a feature of natural climate variability in Australia, and although there have been a few record high rainfall events in the past decade, the observational record is not long enough to show a clear trend in high rainfall extremes.

Drought is another prominent feature of Australia's climate, with the most severe droughts in the agriculturally productive east and south often related to the El Niño phase of the ENSO phenomenon. El Niño-related droughts in these areas have occurred since the beginning of the instrumental record, but particularly severe such events occurred during the 1982-1983, 1992-1994, 2002-2003 and 2006-2007 periods. These more recent droughts are embedded in a recent 15-year drying trend and come after experiencing 40 years of generally wetter-than-average seasons. In the current series of droughts, as happened in the first half of the twentieth century, there is often a weaker recovery period in between droughts, but the droughts themselves are becoming more intense due to the higher temperatures. For example, a severe drought in 2002-2003 has seen a weak recovery and then slide back into severe drought conditions in 2006-2007 in southern and eastern Australia. Taking the period March 2006 to February 2009, large areas of western, southern and eastern Australia were at or below decile 1 rainfall.

The series of droughts in southeast Australia is of particular concern for irrigated agriculture as it is having serious impacts on water availability in the Murray-Darling Basin (MDB), historically one of the most agriculturally productive regions of the country. During the 2000-2007 period, the average annual inflow in the river systems of the MDB was only $4150 \mathrm{GL}$ year $^{-1}$, compared to a longterm post-1950 average of about $12,300 \mathrm{GL}_{\text {year }}{ }^{-1}$. In the April 2006-March 2007 period, inflow reached a record low of only $770 \mathrm{GL}_{\text {year }}{ }^{-1}$ (Cai and Cowan 2008).

\section{The unfolding of climate risks through twenty-first century}

The most significant climate risks to Australian agriculture through the twenty-first century, particularly those that could be considered dangerous, are best defined by the producers and industries themselves. In general, they are associated with climatic features to which producers/ industries show high sensitivity and to which their adaptive capacity is limited. In the consultative processes described earlier (Steffen et al. 2006b), producers/industries identified high rates of change and abrupt shifts in climate as two climatic features that may exceed their adaptive capacity. In addition, they identified two time scales as important: (1) within-season variability and reliability and (2) longterm trends in moisture availability. Improving their capacity to adapt to climatic changes on these time scales will be crucial in determining how well they will cope with climate change through the century. Here, we focus on observed climatic changes in the most recent few decades to analyse the significance of these risks, as well as to provide some insights into how producers and industries might adapt.

In terms of changes in rainfall at the shorter time scale, a key message that emerged from the consultation process is that within-season reliability is seen as more relevant to agriculture than variability, where the latter is commonly expressed as annual or seasonal totals. Reliability refers to 
the distribution of rainfall through the growing season. For example, two locations may both have an average of $125 \mathrm{~mm}$ of rain in the winter growing season (June-JulyAugust). For one location, the probability of receiving at least $25 \mathrm{~mm}$ of rain in each of June, July and August may be 8 years out of 10 , whereas in the other location it may only be 2 years out of 10 . Thus, the rainfall reliability is much greater for the former than for the latter.

It was also noted that reliability is generally more closely related to plant growth than variability. Therefore, if regional shifts in climate reliability are already occurring, there would be immediate consequences for on-farm management practices, industry investment and development plans, as well as government policy making, particularly if these shifts in reliability are consistent with expectations of climate change.

Typically, reliability is expressed in conditional terms, like the likelihood of $30 \mathrm{~mm}$ or more in each month of a season or at least $50 \%$ of the respective long-term monthly means in each month of a season (Laughlin et al. 2003). Figure 5 shows a time series analysis applied to reliability of autumn rainfall over 100 years. It is interesting that the apparent trends seem to be regional in nature, implying that changes in reliability, whether due to underlying climate change or other factors, can be mapped. The figure treats the 100 years as a single time series and displays a (single) overall trend in the series but it is possible to estimate the reliability for parts of the series, such as the last 25 years or the first 50 years. Knowledge about how rainfall reliability is changing along with enhanced adaptive capacity may allow producers to deal successfully with climatic changes that, on the surface, might be considered "dangerous".
It is now well established that the proximate cause of the decrease in rainfall over southeast Australia is an increase in persistent, intense high pressure systems over the region (Nicholls 2009). Earlier research had proposed a link between these high pressure systems and the warmer sea surface temperature in the central equatorial Pacific Ocean, which is probably part of the general surface ocean warming trend associated with climate change (Watkins 2005). In effect, global warming is leading to more persistent El Niño-like conditions. However, research in the last 2 years has pointed towards changes in the IOD and SAM modes of variability as being the dominant factors in driving the ongoing pattern of severe drought (Ummenhofer et al. 2009; Nicholls 2008).

An analysis of rainfall patterns from the early twentieth century to the present shows a striking relationship between the IOD mode that leads to enhanced tropical moisture transport across the Australian continent and the observed amount of rainfall. In recent decades, this mode of IOD has been less frequent as the climate has warmed. Changes in the SAM are associated with the dominant midlatitude westerly airflow, which brings significant rainfall to southern and eastern Australia. This airflow appears to have migrated southwards. A similar poleward migration has also been observed in the northern hemisphere, which has led to increased drought in southern Europe. These poleward migrations of the mid-latitude westerlies are expected with a warming climate (Pittock 2003; Cai et al. 2005; Gillett 2005).

Palaeo-climate studies offer some further insights into the observed drying trend. Although ENSO does not now appear to be the sole, or even dominant, factor in the recent
Fig. 5 A time series analysis applied to reliability of autumn rainfall over the past 100 years

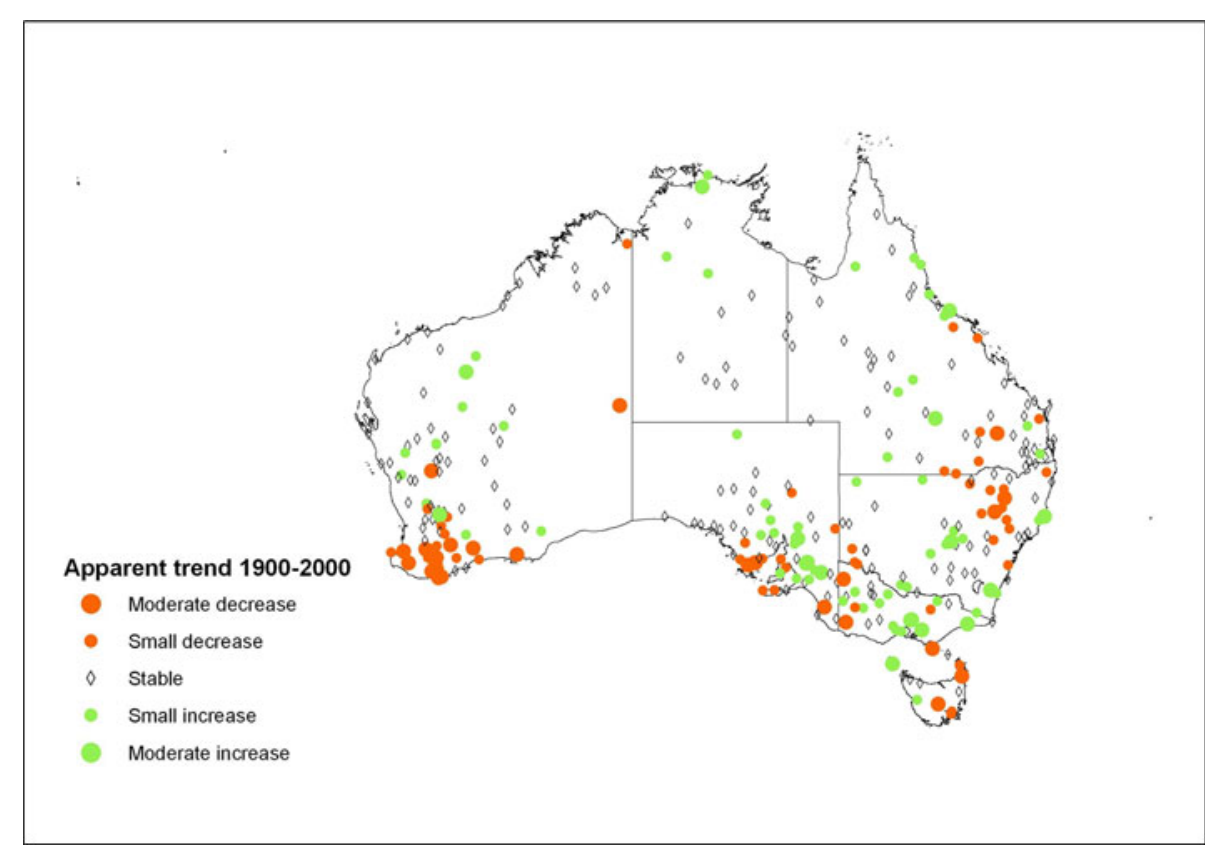


trends, from a longer-term perspective, it may still be important. A study of the global climate during the Pliocene (5-3 million years ago) indicates that the El Niño phase of ENSO was permanent rather than intermittent (Fedorov et al. 2006) during that epoch and associated with persistently warm surface waters in the coastal and equatorial Pacific. Contemporary observations of the heat content of all of the Earth's major ocean basins show temperature increases in the surface waters over the past 50 years (Barnett et al. 2005). For the Pacific Ocean, significant increases (ca. $0.2^{\circ} \mathrm{C}$ ) have occurred in the top $100 \mathrm{~m}$ or so. These observations suggest an increasing risk that the El Niño phase will become more frequent or even persistent in the future with climate change, which is consistent with the observed change to a more negative Southern Oscillation Index-more frequent and intense El Niño events-over the past 50 years (McPhaden et al. 2006)

Finally, in some important aspects, GCM-based model projections are in agreement with the observed trends, increasing the confidence in those aspects of the projections. For example, model projections for the Australian region show that a decrease in precipitation in eastern Australia is accompanied by increased atmospheric pressure (Shi et al. 2008), consistent with the observations. Model projections for the MDB show a 5-15\% reduction in mean annual rainfall by 2060 and a warming trend in the eastern Indian Ocean dipole (Christensen et al. 2007); both of these projections accord with recent observations. Analysis of a suite of climate model projections shows, with a high degree of consistency across the models, a drop in winter rainfall in Victoria and southern South Australia. Again, these projections are in agreement with observations. The ENSO, IOD, SAM and the Subtropical Ridge are features which are represented in the models. Being among the major causes of climate variability in Australia, it is important to note that these features have been shown to be sensitive to climate forcings and will thus be affected by climate change (Toggweiler 2009; Arblaster and Meehl 2006; Son et al. 2008; Ummenhofer et al. 2009; Meyers et al. 2007). The increasing alignment of observations, processes involved in climate variability and model predictions is particularly important when considering the adaptation of agriculture in Australia to climate change.

\section{Conclusions}

Determining what constitutes "dangerous climate change" in the context of Australian agriculture presents some unique challenges. For the vast majority of Australian agricultural enterprises, water availability is a more important climate-related parameter than is temperature per se. Given the complex relationship between the hydrological cycle and climate change and the fact that water availability is affected by many non-climatic processes, determining a temperature level at which changes in water availability seriously affect the viability of Australian agriculture is a daunting task. In addition, the wide variety of agricultural systems practised in Australia means that there is inevitability a very wide range of sensitivities to climate change.

Despite these complications, it is nevertheless desirable to attempt to link the risks that Australian agricultural producers and industries face from a changing climate to changes in mean global temperature. There are some important insights that can be gained by making this attempt:

- The relationship between the drying trend in southeast Australia and climate change has become clearer. Although the connection between El Niño events and drought in eastern Australia is well established, it appears that change in two other modes of natural variability - the Indian Ocean Dipole and the Southern Annular Mode-may be as least as important as ENSO in driving the observed pattern of intensifying drought over the past few decades. The link between changes in these modes of variability and a warming climate system is becoming better established. In terms of agricultural producers and industries, this improving knowledge base adds weight to the seriousness of this risk for continuing and perhaps intensifying drying of some regions in the future.

- The probability of abrupt changes in climate rises with increasing global mean temperature, although the relationship is not straightforward. It may be possible to link an unacceptably high risk of abrupt change to a particular increase in global mean temperature.

- For particular agricultural industries, it may be possible to make more direct connections between the viability of the industry and a rise in global mean temperature. An example may be the dairy industry, where the sensitivity of dairy cattle to heat stress is a key aspect of the industry's vulnerability to climate change. The January 2009 heat wave in Victoria and southern South Australia has highlighted the immediate nature of the threat of temperature extremes.

Finally, it is critical to consider the adaptive capacity of Australian producers and industries when considering the definition of dangerous climate change. Producers and industries have shown considerable adaptability towards climate variability in the past, and there are now an increasing number of more pro-active approaches towards adapting to longer-term climate change and its effects on variability. 
Acknowledgments We thank two reviewers for their helpful comments on an earlier draft of this paper.

\section{References}

Agriculture and Food Policy Reference Group (2006) Creating our future: agriculture and food policy for the next generation. Report to the Minister for Agriculture, Fisheries and Forestry Canberra, Australia

Allen Consulting Group (2005) Climate Change: risk and Vulnerability. Promoting an efficient adaptation response in Australia. Final report to the Australian Greenhouse Office. Department of the Environment and Heritage. Australian Greenhouse Office, Department of Environment and Heritage, Canberra

Arblaster JM, Meehl GA (2006) Contributions of external forcings to southern annular mode trends. J Clim 19(12):2896-2905

Barnett TP, Pierce DW, AchutaRao KM, Gleckler PJ, Santer BD, Gregory JM, Washington WM (2005) Penetration of human-induced warming into the world's oceans. Science 309(5732):284-287

Cai WJ, Cowan T (2008) Evidence of impacts from rising temperature on inflows to the Murray-Darling Basin. Geophys Res Lett 35:L07701

Cai W, Shi G, Cowan T, Bi D, Ribbe J (2005) The response of the Southern Annular Mode, the East Australian Current, and the southern mid-latitude ocean circulation to global warming. Geophys Res Lett 32:L23706

Christensen JH, Hewitson B, Busuioc A, Chen A, Gao X, Held I, Jones R, Kolli RK, Kwon W-T, Laprise R, Magaña Rueda V, Mearns L, Menéndez CG, Räisänen J, Rinke A, Sarr A, Whetton P (2007) Regional climate projections. In: Solomon S, Qin D, Manning M et al (eds) Climate Change 2007: the physical science basis. Contribution of working group I to the fourth assessment report of the intergovernmental panel on climate change. Cambridge University Press, Cambridge, UK and New York, NY, USA, p 996

Clark A, Barratt D, Munro R, Sims J, Laughlin G, Poulter D (2006) Climate change: adaptation in agriculture. Science for Decision Makers. Government of Australia, Bureau of Rural Sciences, Canberra, Australia

Fedorov AV, Dekens PS, McCarthy M, Ravelo AC, deMenocal PB, Barreiro M, Pacanowski RC, Philander SG (2006) The Pliocene paradox (mechanisms for a permanent El Niño). Science 312 (5779):1485-1489

Gillett NP (2005) Climate modelling-Northern Hemisphere circulation. Nature 437(7058):496

Hendon HH, Thompson DWJ, Wheeler MC (2007) Australian rainfall and surface temperature variations associated with the Southern Hemisphere annular mode. J Clim 20(11):2452-2467

Hennessy K, Fawcett R, Mpelasoka F, Jones D, Bathols J, Whetton P, Stafford Smith M, Howden M, Mitchell C, Plummer N (2008) An assessment of the impact of climate change on the nature and frequency of exceptional climatic events. A consultancy report by CSIRO and the Australian Bureau of Meteorology for the Australian Bureau of Rural Sciences

Hennessy KJ, Whetton PH, Preston B (2010) Climate projections. In: Stokes CJ, Howden SM (eds) Adapting agriculture to climate change: preparing Australian agriculture forestry and fisheries for the future. CSIRO Publishing, Collingwood, pp 13-20

Howden SM, Crimp S (2005) Assessing dangerous climate change impacts on Australia's wheat industry. In: Zerger A, Argent RM (eds) MODSIM 2005-Proceedings of the international conference on modelling and simulation. Modelling and Simulation Society of Australia and New Zealand, pp 505-511

Howden M, Jones R (2001) Costs and benefits of $\mathrm{CO}_{2}$ increase and climate change on the Australian wheat industry. Australian Greenhouse Office, Australian Government, Canberra
Kingwell R (2006) Climate change in Australia: agricultural impacts and adaptation. Australas Agribus Rev, vol 14

Laughlin GP, Zuo HP, Walcott J, Bugg AL (2003) The rainfall reliability wizard - a new tool to rapidly analyse spatial rainfall reliability with examples. Environ Model Softw 18(1):49-57

Lilley I (2006) It's life, Jim, but not as we know it. Griffith Rev, vol 12

McKeon GM, Hall WB, Henry BK, Stone GS, Watson IW (2004) Pasture degradation and recovery in Australia's rangelands: learning from history. Queensland Department of Natural Resources, Mines and Energy, Brisbane

McPhaden MJ, Zebiak SE, Glantz MH (2006) ENSO as an integrating concept in Earth science. Science 314(5806):1740-1745

Meyers G, McIntosh P, Pigot L, Pook M (2007) The years of El Niño, La Niña, and interactions with the tropical Indian ocean. J Clim 20(13):2872-2880

Nelson R, Kokic P, Elliston L, Blias A (2005) Structural adjustment: a vulnerability index for Australian broadacre agriculture. Aust Commod 12:171-179

Nicholls N (2008) Recent trends in the seasonal and temporal behaviour of the El Niño-Southern Oscillation. Geophys Res Lett 35:L19703

Nicholls N (2009) Local and remote causes of the southern Australian autumn-winter rainfall decline, 1958-2007. Climate Dynamics (online)

Pittock B (ed) (2003) Climate change: an Australian guide to the science and potential impacts. Australian Greenhouse Office, Canberra

Quiggin J, Horowitz J (2003) Costs of adjustment to climate change. Aust J Agric Resour Econ 47(4):429-446

RA NLW (2001) Australian agriculture assessment 2001, vol 2. National Land and Water Resources Audit, Canberra

Shi G, Ribbe J, Cai W, Cowan T (2008) An interpretation of Australian rainfall projections. Geophys Res Lett 35:L02702

Son SW, Polvani LM, Waugh DW, Akiyoshi H, Garcia R, Kinnison D, Pawson S, Rozanov E, Shepherd TG, Shibata K (2008) The impact of stratospheric ozone recovery on the Southern Hemisphere westerly jet. Science 320(5882):1486-1489

Steffen W, Love G, Whetton P (2006a) Approaches to defining dangerous climate change: a southern hemisphere perspective. In: Schellnhuber HJ, Cramer W, Nakicenovic N, Wigley T, Yohe $\mathrm{G}$ (eds) Avoiding dangerous climate change. Cambridge University Press, Cambridge, pp 219-225

Steffen W, Sims J, Walcott J (2006b) Farming profitably in a changing climate: a risk-management approach. Department of Agriculture, Fisheries and Forestry, Canberra

Toggweiler JR (2009) Shifting westerlies. Science 323(5920): 1434-1435

Ummenhofer CC, England MH, McIntosh PC, Meyers GA, Pook MJ, Risbey JS, Gupta AS, Taschetto AS (2009) What causes southeast Australia's worst droughts? Geophys Res Lett 36:L04706

UNFCCC (1992) The United Nations framework convention on climate change

Walcott J (2004) Diversity of grain cropping in Australia as an indicator of sustainability. In: Fischer T, Turner N, Angus J et al (eds) New directions for a diverse planet. 4th international crop science congress Brisbane, Australia, 2004. The Regional Institute Ltd

Walcott JJ, Wolfe EC (2008) Estimating adaptive capacity in Australian farming environments. In: Unkovich M (ed) Global issues, paddock action. Proceedings of the 14th Australian agronomy conference 21-25 September. Australian Society of Agronomy, Adelaide

Walcott J, Zuo HP, Rath H (2001) Recent changes in agricultural land use in Australia. In: 10th Australian agronomy conference, Hobart, Tasmania, 2001. Australian Society of Agronomy

Watkins AB (2005) The Australian drought of 2005. Bull World Meteorol Organ 54(3):156-162 